\title{
ЛЕКСИКОЛОГІЯ
}

\section{РЕСЕМАНТИЗАЦІЯ РЕЛІГІЙНОЇ ЛЕКСИКИ В АНГЛІЙСЬКІЙ МОВІ}

Дослідницьку увагу сфокусовано на адаптації оновленої релігійної лексики англійської мови до сучасних особливостей сприйняття і передачі інформації. Мета наукової розвідки - описати процес ресемантизації релігійної лексики в сучасній англійській мові. Аргументовано, що тексичні одинииі релігійного контексту характеризують англійську мову як динамічну систему. Встановлено, щз проиес ресемантизації може спричинитися до виникнення нової самостійної тексичної одиниці. Практична значущість статті полягає в тому, що результати дослідження можуть стати матеріалом для розробки лекиій та семінарів, присвячених особливостям релігійної тексики.

Ключові слова: лексема, релігійна тексика, ресемантизачія, релігійний контекст, система.

Boichuk M. Resemantisation of Religious Vocabulary in English. The relevance of the study is described by the communicative range of covered issues and the adaptation of updated religious vocabulary in English to modern rates of perception and transmission of information.

The purpose of this study is to consider the specific features of the representation of religious vocabulary in English translation dictionaries and to analyse the process of resemantisation of English lexical units.

With the development of religious trends, knowledge, and schools a lexicon of this sphere is developed. Various reference books, dictionaries, and encyclopaedias cover the standardisation and study of units of resemantisation of the religious sphere. The analysis of this segment is quite diverse, in particular, it includes history and problematics, social significance, and the study of church subject matter. Lexical semantics of English religious culture are qualified by conditioned register units of lexicographic sources of explanatory nature. The recognition of the procedure for identifying resemantic component values lies in the sequential compilation of words utilising typical identifiers with the most generalised nature. Each lexical unit is determined by a certain coherence and independence, forming certain groups within the semantic space. After all, religious vocabulary is one of the oldest parts of the system in English, which develops according to general trends and laws that allow the coverage and study of important elements of verbalisation of religious mentality and worldview. 
Religious lexemes occupy an important place, some of them are used to this day, most of them are registered in modern general lexicographical works. Many of them have remained out of the register of modern sources, or have undergone the process of updating obsolete names. A resemantic system of words is a network of semantic relations that are traced between words of a certain structure or system, which should be described in terms of semantic relations. Since the lexeme is an external reflection of the word, its inner side is illuminated by the sememe, which is the smallest and equivalent unit of meaning of the word and the lexical-semantic tier. The practical significance of the article is that the results of the study can be the basis for the development of lectures and seminars in the study of religious vocabulary.

Keywords: lexeme, religious vocabulary, resemantisation, religious context, system.

\section{Вступ}

Релігійна лексика становить цілісну систему із взаємозалежними процесами, що мають певні властивості та підлягають законам існування цієї цілісності. Ї̈̈ склад обумовлює представлена тематика, де передусім порушені проблеми духовності, етики, віри, церковного життя, висвітлені норми моралі (Bryson, 2019). В умовах сучасних реалій релігійна лексика виконує нові професійні завдання, що раніше не входили в коло іï компетентності (Fries, 2020; Hockett, 2018).

Семантичні процеси, що відбуваються в мові, мають універсальний характер і конкретний прояв набуття словом нового значення (Lehrer, 2018; Ullman, 2019). Фактором оновлення релігійної лексики виступають екстралінгвальні чинники (сукупність різноманітних імпульсів із навколишнього середовища, які пов'язані з особливостями історичного розвитку суспільства, міграціями населення, змінами форми спілкування тощо), що відіграють визначну роль у комунікації. Досліджувана лексика в англійській мові має архаїчно-піднесене та емоційне значення, створюючи при цьому експресивний ефект (Chomky, 2018). Нині відстежується зацікавленість до процесу ресемантизації на рівнях, що раніше не були розглянуті з певних історично-соціальних причин. На думку Н. В. Піддубної, релігійна лексика відрізняється від інших тим, що спрямована до сфери таємного (2019). А. А. Ковтун стверджує, що сьогодні релігійні лексеми належить до тих лексичних елементів, «які безпосередньо відображають найбільш активні прояви сучасного життя» (2018).

Незважаючи на те, що численні праці присвячено вивченню релігійної лексики, особливості оновлення цих одиниць в англійській 
мові до сучасних темпів сприйняття і передачі інформації висвітлено недостатньо, що зумовлює потребу подальшого аналізу у відповідному ракурсі й засвідчує актуальність дослідження. Мета цієї наукової розвідки - схарактеризувати процес ресемантизації релігійної лексики в сучасній англійській мові. Поставлена мета зумовлює виконання таких завдань: 1) виявити концептуально-семантичні властивості релігійної лексики англійської мови; 2) дослідити процес ресемантизації, що бере участь у поповненні терміносистеми сучасної англійської мови.

\section{Методи дослідження}

У роботі застосовано семантичний аналіз, що дав змогу виявити складники значень слів. За допомогою лінгвістичного методу процес ресемантизації було досліджено в релігійному контексті як один із найбільш поширених варіантів поповнення терміносистеми сучасної англійської мови. Структурно-семантичний і функційно-семантичний підходи до вивчення релігійної лексики дали змогу виділити тенденції та закономірності семантичних змін досліджуваних одиниць в англійській мові.

\section{Виклад основного матеріалу}

Завдяки усвідомленню особливостей сучасного англомовного релігійного дискурсу можна виділити рефлексивні явища, що зводяться до раціональних механізмів обгрунтування та пояснення процесу ресемантизації. Терміносистема релігійної лексики є структурно впорядкованою і виступає у вигляді функційно-семантичних полів. Для них характерна складна структура, зумовлена наявними ядерною та периферійною зонами, на різних рівнях яких перебувають терміни, що належать до певних тематичних груп у їх складі (Lyons, 2019; Fillmore, 2018).

Механізм ресемантизації передбачає актуалізацію мало використовуваних або застарілих мовних одиниць. Зберігаючи попередній семантичний зміст або повністю змінюючи його, вони переживають відродження і поповнюють словниковий запас мови. Ресемантизація зумовлена результатом семантичного зсуву та дезактивацією первинної номінації (Баш та ін., 2009). Дотримуючись дефініції термінів Н. І. Жабо (2014), релігійні одиниці визначаємо як одиниці мови тематичної сфери вживання, що виступають найменуванням словесного 
поняття, маючи певне закріплене термінологічне значення. Структурно впорядкована підсистема й граматичних, і лексичних одиниць, об’єднаних однією спільною семою 'релігія', виконує номінативну функцію та передбачає сувору відповідність поняттям (Lakoff, 2019; Meyer, 2020).

На сьогодні теорія термінографічної семантики починає активно усталюватися, тому лише частина релігійних визначень в англійській мові концептуально задана й зафіксована в словниках. Наприклад: Altar - a table or platform used in a church service or ceremonial rite; Bishop A high-ranking Christian cleric, in modern churches usually in charge of a diocese; Prophet - a religious leader and spokesperson; Gospel - a written account of the life of Jesus. Зв'язок когнітивної і комунікативної функцій термінів дає змогу зауважити те, що роль ресемантизації спрямована на формування релігійного мислення особистості (Palmer, 2019). Типологічне різноманіття термінів задає певний перелік моделей, що забезпечують розуміння інформації про релігійне поняття і реалізують текстові комунікативні ситуації.

Завдяки експансії лексема проходить процес ресемантизації, і неологізм миттєво засвоюється релігійним суспільством (Thoiron, 2019; Ullman, 2018). Лексичні елементи, що піддаються цьому процесу, мають певні властивості: наявність акронімів і значної кількості абревіатур, особлива структура побудови тексту, часте вживання конструкцій пасивного стану, емоційність. Наприклад: JC - Jesus Christ, LDS - Latter Day Saints, MK - Missionary Kid, NIV - New International Version (of the Bible), PRAY - Praise, Repent, Ask, Yield, PK - Preacher's Kid. Процесу ресемантизації притаманне постійне прагнення до максимально точного й оновленого відтворення поняття.

Концептуальна закріпленість і цілісність релігійних лексичних понять в англійській мові підтверджується комплексними дослідженнями лінгвістів. Параметри термінів відрізняються своєю структурою, особливостями й змістом. Їхні складники параметричні, регулярні та універсальні. Наприклад: deacon - a priest who holds the lowest level of the church hierarchy; paterik - a collection of short religious and instructive stories; funeral service - worship for the dead (Cross and Livingstone, 2005). Тематична лексика представлена достатньо неоднорідно, що характеризується різним понятійним наповненням (Малатий, 2020). 
Способи термінологічної номінації мають комплексну тенденцію до розширення значення слова - від моносемантичних до полісемантичних одиниць (Kareva, 2018). Спеціальні терміни певних наук можуть стати термінами церковної тематики за умови, що фрагмент цього контексту особливо важливий у цьому використанні. Наприклад: court, image, marriage, recluse, victim. Вагомим положенням для вибору способів класифікації лексичних понять за тематикою $є$ те, що системи мов перебувають у постійному процесі формування та реорганізації, відтворюючи швидкий розвиток самої сфери (Shelov, 2019; Evans, \& Green, 2020).

Дослідження показало, що ресемантизація торкнулася саме тих понять, які належать до поля віри. Наприклад, лексеми, що об’єднують характеристики теономічного суб'єкта - divine, holy, celestial, sacred; назви істот, яким приписують надприродні властивості - angel, saint, oracle, creator, apostle; лексеми, що позначають істотні властивості надприродного відносно людини - mercy, regeneration, call, atone, grace; лексеми, які стосуються оформлення віровчення - creed, rite, canon. Динаміка запропонованих термінів виводить їх за межі відповідного поля, тому логічним є репрезентація конкретної сфери функціювання.

Ресемантизація $є$ результатом семантичного зсуву або дезактуалізації первинної номінації. Наприклад, значення, що об’єднують характеристики лексеми holy (первинне значення пов'язане з давньоанглійським hal та давньонімецьким heil, які вказують на здоров'я, щастя, удачу): 1) «який належить кому-, чому-небудь, походить від, асоціюється із божественною силою»; 2) «відноситься до почитання або має специфічну релігійну ціль»: a holy book; a holy place; 3) життя або діяння з високоморальною або духовною ціллю»; 4) який заслуговує спеціальної поваги або благоговіння»: the pursuit of peace is our holiest quest (Малатий, 2020). Процес ресемантизації простежуємо у висловах: holy water («свята вода; вода для зцілення, відновлення здоров'я»), the Most Holy Mother of God («Найсвятіша Божа мати; Рятівниця від болю, печалі та скорботи»).

Ще один приклад - ресемантизація лексеми doctrine. У період Реформації та Просвітництва чимало загальновживаних лексем зазнали обмеження релігійною сферою використання і / або набули специфічного релігійного значення. Зокрема, іменник doctrine початково означав 'навчання, освіта, інструктаж', проте набув конкретизованого 
церковного значення 'сукупність принципів чи вірувань, особливо релігійних' (OED). Зараз ця лексеми знову відходить у значенні від релігіï: the legal doctrine of joint criminal enterprise (Macmillan Dictionary, 2021).

Під час розгляду ресемантичного розвитку певної лексичної одиниці виникає логічний вибір етимону проаналізованого терміна як його основи. У такому разі найчастіше виникає проблема початкового значення. Етимон не відповідає домінувальному контексту слова. 3 опертям на такі передумови з'являється ймовірність, що етимон перебуває не в полі зору семантики й розглядається лише як формальний аспект походження поняття. Він виступає початковим значенням з позиції дійсності й указує на елементи, які формують цілісне уявлення про релігійний об’єкт (Darmesteter, 2019). Установлення вихідного значення терміна не дає чіткого розуміння кількості похідних ресемантичних компонентів, адже вихідне значення вважається комплексною сукупністю відліку розвитку, що представляє декілька процесів, об’єднаних значенням.

Релігійній лексиці властиві потенційна здатність до детермінологізації та емоційна конотація в процесі історичного розвитку (Escourbas, 2018). Вона виступає частиною культурно-національного коду англійської мови, що реалізується різною функційною мірою. Крім того, релігійна лексика активно поповнює сучасні словникові реєстри, наприклад: Basilians, Eucharist, arthos, agiosm, blessed altar cloth (Collins English Dictionary, 2021; Macmillan Dictionary, 2021; Oxford English Dictionary, 2021).

Мінливість і динамічність є невід’ємними рисами лексичної релігійної системи сучасної англійської мови. Унаслідок впливу різних причин екстралінгвального характеру поняття зазнали ресемантичних змін, що посприяло частковій перебудові лексичного рівня, з'явилася велика кількість неологізмів, актуалізувалися старі й виникли нові значення слів. Саме тому процес ресемантизації може спричинитися до виникнення нової самостійної лексичної одиниці.

\section{Висновки}

У результаті проведеного дослідження було встановлено, що тематичні терміни є продуктами зміни семантичної структури, зокрема процесу ресемантизації, завдяки якому відбувається збагачення 
терміносистеми. Уживання лексики в різних контекстах сприяє розвитку лексичної семантики, вузькоспеціальні одиниці мови популяризуються та входять у вжиток.

Ресемантизація ідеологічних компонентів значень представлена основною причиною збереження релігійних понять в активній частині лексикону англійської мови. На функціювання цієї лексики суттєво впливають соціальні чинники, які сприяють переходу слова з пасивного складу мови до активного, де значення вже не сприймається як застаріле. Це явище розширює коло контекстів, у яких воно може функціювати й змінюватися.

Подальші дослідження плануємо спрямувати на аналіз семантичної деривації в релігійній лексиці української мови.

\section{ЛІТЕРАТУРА}

1. Баш, Л., Боброва, А., Вечеслова, Г., Кімягарова, Р., \& Сендровіц, О. (2009). Современный словарь иностранных слов: Толкование, употребление, словообразование, этимология. Киев: Феникс. 2. Жабо, Н. І. (2014). Бесплатный поиск эквивалента при переводе терминов с учетом фактора ресемантизации. Вестн. Рос. ун-та дружбы народов. Серия «Экология и безопасность жизнедеятельности», 4, 141-149. 3. Ковтун, А. А. (2018). Розвиток лексичних релігійних дериватів в українській мові. Лінгвістичні дослідження, 48, 99-107. https://doi.org/10.5281/zenodo.1242819. 4. Малатий, Т. Й. (2020). Словник церковних термінів. Олександрія: Александрія. 5. Піддубна, Н. В. (2019). Парагматичні та синтагматичні зв'язки як вияв системності бібліїзмів української мови. Studia Ukrainica Posnaniensia, VII, 127-136. 6. Bryson, B. (2019). Made in America. Random house books. London: Transworld Publishers. 7. Chomky, G. O. (2018). Aspects of the theory of syntax. Cambridge: The N. I. I. Press. 8. Collins English Dictionary. (2021). Узято 3 https://www.collinsdictionary.com/dictionary/english. 9. Cross, F. L., \& Livingstone, E. A. (2005). The Oxford Dictionary of the Christian Church. Oxford: Oxford University Press. 10. Darmesteter, A. (2019). The life of words studied in their meanings. Paris: YMCA-Press. 11. Escourbas, M. P. (2018). The state of the English language at the end of the 20 th century linguistic and cultural aspects. New York: NY Publishing. 12. Evans, V., \& Green, M. (2020). Cognitive linguistics: an introduction. Edinburg: Edinburg University Press. 13. Fillmore, Ch. (2018). Dynamic phenomena in the basis of religious vocabulary of the late $20^{\text {th }}-$ early $21^{\text {st }}$ centuries. New York: NYPublishing. 14. Fries, Ch. C. (2020). The structure of English: An introduction to the construction of English sentences. London: Transworld Publishers. 15. Hockett, Ch. (2018). A course in modern linguistics. New York: Oxford \& IBH PublishingCo. 16. Kareva, O. M. (2018). Lexico-semantic changes in the names of persons socially sphere. London: Transworld Publishers. 17. Lakoff, G. (2019). Semantic and axiological modifications of the interpretation of religious vocabulary in contemporary dictionaries. London: Transworld Publishers. 18. Lehrer, A. (2018). Semantic fields and lexical structure. Amsterdam: Basic Books. 19. Lyons, J. (2019). Language and linguistics. An Introduction. Cambridge: Cambridge University Press. 20. Macmillan Dictionary. 
(2021). Узято 3 https://www.macmillandictionary.com/. 21. Meyer, I. (2020). Methods of lexicographic actualization of religious vocabulary. Deli: Indiana University Press. 22. Oxford English Dictionary. (2021). Узято з https://dictionary.cambridge.org/dictionary/english/. 23. Palmer, F. R. (2019). Semantics: A new out line. California: Standford University Press. 24. Shelov, S. D. (2019). Out-of-linguistic determinism of terminological systems. Cambridge: Cambridge University Press. 25. Thoiron, Ph. (2019). Multilingual terminologies and archi-concept: Some cognitive aspects of research in terminology. Paris: YMCA-Press. 26. Ullman, S. (2019). Pragmatic functions of cultural linguistic representations of the functionally semantic field. Oxford: Oxford University Press. 27. Ullman, S. (2018). Semantics. The introduction into the science of meaning. New York: NY Publishing.

\section{REFERENCES}

1. Bash, L., Bobrova, A., Vecheslova, H., Kimyagarova, R., \& Sendrovits, O. (2009). Sovremennyj slovar' inostrannyx slov: Tolkovanie, upotreblenie, slovoobrazovanie, e'timologiya [Modern dictionary of foreign words: Interpretation, use, word formation, etymology]. Kiev: Phoenix [in Russian]. 2. Zhabo, N. I. (2014). Besplatnyj poisk e'kvivalenta pri perevode terminov s uchetom faktora resemantizacii [Free search for an equivalent when translating terms taking into account the factor of resemantization]. Vestn. Ros. un-ta druzhby narodov. Seriya «E'kologiya i bezopasnost' zhiznedeyatel'nosti» - Bulletin of Peoples' Friendship University of Russia. Series «Ecology and Life Safety», 4, 141-149 [in Russian]. 3. Kovtun, A. A. (2018). Rozvytok leksychnykh relihiinykh deryvativ v ukrayinskii movi [Developmen of flexical religious derivatives in the Ukrainian language]. Linhvistychni doslidzhennia - Linguistic Research, 48, 99-107. https://doi.org/10.5281/zenodo.1242819 [in Ukrainian]. 4. Malatyi, T. Y. (2020). Slovnyk tserkovnykh terminiv [Dictionary of church terms]. Olexandriia: Aleksandriia [in Ukrainian]. 5. Piddubna, N. V. (2019). Parahmatychni ta syntahmatychni zvyazky yak vyшav systemnosti bibliizmiv ukrainskoi movy [Paradigmatic and syntagmatic relationships as a manifestation of the systematicity of Bibleisms of the Ukrainian language]. Studia Ukrainica Posnaniensia, VII, 127-136 [in Ukrainian]. 6. Bryson, B. (2019). Made in America. Random house books. London: Transworld Publishers [in English]. 7. Chomky, G. O. (2018). Aspects of the theory of syntax. Cambridge: The N. I. I. Press [in English]. 8. Collins English Dictionary. (2021). Retrieved from https:// www.collinsdictionary.com/dictionary/english [in English]. 9. Cross, F. L., \& Livingstone, E. A. (2005). The Oxford Dictionary of the Christian Church. Oxford: Oxford University Press [in English]. 10. Darmesteter, A. (2019). The life of words studied in their meanings. Paris: YMCA-Press [in English]. 11. Escourbas, M. P. (2018). The state of the English language at the end of the 20 th century linguistic and cultural aspects. New York: NY Publishing [in English]. 12. Evans, V., \& Green, M. (2020). Cognitive linguistics: an introduction. Edinburg: Edinburg University Press [in English]. 13. Fillmore, Ch. (2018). Dynamic phenomena in the basis of religious vocabulary of the late $20^{\text {th }}$ - early $21^{\text {st }}$ centuries. New York: NY Publishing [in English]. 14. Fries, Ch. C. (2020). The structure of English: An introduction to construction of English sentences. London: Transworld Publishers [in English]. 15. Hockett, Ch. (2018). Acourse in modern linguistics. New York: Oxford \& IBH Publishing Co [in English]. 16. Kareva, O. M. (2018). Lexico-semantic changes in the names of persons socially sphere. London: Transworld Publishers [in English]. 17. Lakoff, G. (2019). Semantic and axiological modifications of the interpretation of religious vocabulary in contemporary 
dictionaries. London: Transworld Publishers [in English]. 18. Lehrer, A. (2018). Semantic fields and lexical structure. Amsterdam: Basic Books [in English]. 19. Lyons, J. (2019). Language and linguistics. An Introduction. Cambridge: Cambridge University Press [in English]. 20. Macmillan Dictionary. (2021). Retrieved from https://www.macmillandictionary. $\mathrm{com} /$ [in English]. 21. Meyer, I. (2020). Methods of lexicographic actualization of religious vocabulary. Deli: Indiana University Press [in English]. 22. Oxford English Dictionary. (2021). Retrieved from https://dictionary.cambridge.org/dictionary/english/ [in English]. 23. Palmer, F. R. (2019). Semantics: A new outline. California: Standford University Press [in English]. 24. Shelov, S. D. (2019). Out-of-linguistic determinism of terminological systems. Cambridge: Cambridge University Press [in English]. 25. Thoiron, Ph. (2019). Multilingual terminologies and archi-concept: Some cognitive aspects of research in terminology. Paris: YMCA-Press [in English]. 26. Ullman, S. (2019). Pragmatic functions of cultural linguistic representations of the functionally semantic field. Oxford: Oxford University Press [in English]. 27. Ullman, S. (2018). Semantics. The introduction into the science of meaning. New York: NY Publishing [in English].

Бойчук Мар'яна Ігорівна - асистент кафедри англійської філології та методики навчання англійської мови, Тернопільський національний педагогічний університет ім. В. Гнатюка; вул. Максима Кривоноса, 2, м. Тернопіль, 46027, Україна.

Tel.: +38-035-243-58-80

E-mail: boichuk7396-1@tanu.pro

http://orcid.org/0000-0001-5117-8712

Boichuk Mariana Ihorivna - Teaching Assistant at the Department of English Philology and Methods of Teaching English, Ternopil Volodymyr Hnatiuk National Pedagogical University; 2 Maxyma Kryvonosa Str., Ternopil, 46027, Ukraine.

Надійшла до редакції 2 вересня 2021 року

\section{CITATION}

ДСТУ 8302:2015: Бойчук М. І. Ресемантизація релігійної лексики в англійській мові. Лінгвістичні дослідження: зб. наук. пр. Харк. нац. пед. ун-ту імені Г. С. Сковороди. Харків, 2021. Вип. 55. С. 3-11. DOI: https://doi.org/10.34142/23127546.2021.55.01

APA: Бойчук, М. І. (2021). Ресемантизація релігійної лексики в англійській мові. Лінгвістичні дослідження, 55, 3-11. DOI: https://doi.org/10.34142/23127546.2021.55.01 